\title{
NON-AGENDA
}

With the view of causing an increase to take place in the mass of national wealth, or with a view to increase of the means either of subsistence or enjoyment, without some special reason, the general rule is, that nothing ought to be done or attempted by government. The motto, or watchword of government, on these occasions, ought to be - Be quiet...Whatever measures, therefore, cannot be justified as exceptions to that rule, may be considered as non-agenda on the part of government.

— Jeremy Bentham (c.1801)

\section{Free Trade Agreements and Investment: A Chinese Perspective}

\section{Parikshit Basu, John Hicks and Richard Sappey}

$\mathrm{I}$

n line with the current world-wide drive towards bilateralism, the governments of Australia and China are seeking to establish a bilateral Free Trade Agreement (FTA). An objective of the proposed FTA is to stimulate a greater flow of foreign direct investment (FDI) between the two countries. Although research is inconclusive, this objective is important for growth in both economies. There is also an extensive body of literature on identification of preconditions for successful development of FDI between nations and how it may be encouraged.

Lloyd (2006) believes that international capital flows are important. But he argues that policies to enhance both trade and capital flows are dependent on an environment that fosters supportive, independent and informed public opinion. He notes that the Australia-China FTA Joint Feasibility Study involved a new style of public enquiry into bilateral or regional proposals calling for public submissions. He argues that there should be a process of public enquiry for direct investment flows, but points out that, in Australia, 'there is no practice of public enquiry remotely like that in the field of goods-trade policy' (p. 14). While the Australian Government has canvassed opinions on trade issues related to the Australia-China FTA, there has been less attention to opinions on investment flows. More importantly, there has been almost no consideration of whether the proposed agreement has public support in China, especially in relation to FDI.

From an Australian perspective, it would be useful to know if the Chinese public holds views that support the trade and investment policies likely to be established in a China-Australia FTA. What is the strength of public support for

Parikshit Basu is Senior Lecturer, John Hicks is Dean and Richard Sappey is Research Assistant in the Faculty of Commerce at Charles Sturt University, Bathurst, Australia. 
such an agreement and the extent to which it is thought to be mutually beneficial to trade and investment flows? Are the Chinese people prepared to accept wideranging changes to their economic, legal and social institutions to permit the effective operation of an FTA? In essence, it would be useful to know if the accepted elements of what writers would describe as good international trade and investment policies have been assimilated by those groups in Chinese society whose opinion is likely to be important in the development of Chinese policy. The importance of public opinion in China cannot be discounted, especially when that public opinion is increasingly subject to the influence of China's growing population of tertiary educated professionals whose opinions cannot be ignored by an effective government even if the mechanism for the transmission of opinion is far less transparent than the holding of a public enquiry along Australian lines.

The purpose of this paper is to determine if evidence exists within a specified cohort of the Chinese population (tertiary business students and tertiary business academics) of values and expectations that are considered important by western writers in framing public opinion on which effective international trade and investment policies can be based. Relevant issues that western writers consider important in debates on trade and investment are reviewed in the next section. This is followed by an elaboration of our methodology for conducting the enquiry, a reporting and discussion of our results and, finally, some concluding comments.

\section{Relevant Issues}

For many years economists have speculated on the relationship between FDI and trade. Bajio-Rubio and Montero-Muñoz (2001) argue that no consensus has yet emerged. They point out that there have been arguments, with or without empirical support, advancing the view that increased flow of FDI between two countries enhances trading relationship as well as the reverse view that it is trade development that gives rise to greater capital flows between countries. A third view that the causation runs both ways, can also be found in the literature. Somewhat rarer, however, is the argument that there is no relationship between the two. Overall, the strongest argument is that both effects apply at different stages.

In general, the empirical findings, as summarized by Rob and Vettas (2003), are mixed, with some studies supporting the complementarity argument and others supporting the substitution argument. A finding of particular interest is that the relationship between FDI and trade is more pronounced in economies with a trade orientation and that this was particularly so for Southeast Asian countries (De Mello and Fukasaku, 2000). A more recent paper by Pantulu and Poon (2003) suggests that the trade-creating effects of FDI are dominant, but that the impact varies across countries. Lewer and Terry (2003), when considering the question in the context of the ASEAN nations, conclude that financial liberalisation has resulted in increased trade activity. Other writers who found elements of FDI policy to be important included Cheng and Kwan (2000a), Kerr and Peter (2001) and Zhang (2001). While most of these writers focused on policies for greater openness in the economy, Ma (2000) focused on policies that gave rise to greater 
efficiency within the economy. Thus, a first issue is, do the Chinese perceive a link between trade and FDI? Will they, for example, encourage freer capital movements, as part of an FTA, to enable the full benefits of internationalisation to be gained or are they likely to retain controls over the capital account that restrict capital movements and limit the impact of a more open trade policy?

In considering whether to operate in another country, a firm must take into account the related disadvantages. Even in countries with the same language and similar cultures, miscommunication and poor understanding of local laws remain problems. The problems are exacerbated when the language is different, the culture unfamiliar and the legal system is largely unknown. As Binh and Haughton (2002) point out, these problems increase the cost of doing business and there may be less expensive ways of achieving the goals other than setting up a subsidiary in an uncertain and foreboding location. Consequently, investment will not take place unless the firm has some advantage that offsets increased costs. They explain that the offset must be a 'firm specific' advantage that cannot be readily replicated by a local firm establishing in the same industry. Such advantages may include secret technology, specific managerial know-how, access to markets outside the country of production, a pool of talented staff, economical and secure access to capital and an ability to spread risks by diversifying production locations. What attractions might Australian firms identify to give them an advantage in the Chinese market? Alternatively, do the Chinese perceive advantages (or disadvantages) in establishing operations in Australia?

There are other factors that will determine the choice of location. Binh and Haughton (2002), following Chakrabarti (2001), identified them as openness, market size, macroeconomic variables (macroeconomic stability, exchange rate, and savings rate), GDP growth, tax incentives, geography, natural resources, low wages, good infrastructure, policy reforms and the nature of institutions. While there is some evidence supporting each as being an important determinant of FDI, there remains significant variability in their importance. Cheng and Kwan (2000a) found the existing quality of infrastructure to be important in the case of China, whilst Zhang (2000) argued that a range of infrastructure improvements were a stimulus to FDI. Ma (2000) found that infrastructure was one of the more important factors attracting FDI to different regions within a country. Are policies likely to be put in place that will encourage the development of additional infrastructure and thus, will be conducive to attracting FDI?

The host country's labour market has been widely studied as a determinant of FDI with a range of studies finding that low labour costs are a major contributor to the allocation of FDI. Sethi et al (2003) note the strength of relatively low labour costs and attempts to secure early market entry by US multinational enterprises in Asia. Gao (2002) studied the impact of labour quality in relation to FDI in China and found that it is an important factor in attracting FDI, especially from western countries. However, he notes that earlier studies by Cheng and Kwan (2000a and 2000b) had found that FDI was attracted to China's regions by the size of regional markets, the quality of transportation infrastructure and FDI policy, but not by labour quality. Kerr and Peter (2001) reported that FDI in China seemed to be 
influenced by wage levels as well as exchange rate, taxation regime and the degree of openness of the economy. And Ma (2000) found that the labour costs and quality of the labour force were important contributors in attracting FDI. How important do the Chinese think the availability of cheap labour is? Are they likely to be prepared to encourage or permit capital inflow seeking to take advantage of a cheap labour resource? Is investment to exploit labour the type of FDI that Australians would be expected (or want) to pursue in China?

From an external perspective, where FDI is not seeking access to lower cost resources, it is almost always endeavouring to capture a share of the host country's market. Some researchers have found evidence that market size is an important factor (Cheng and Kwan, 2000a; Zhang 2001; Taylor 2003). They argue that the Chinese market, expanded as a result of Government action, was certainly attractive to investors. Do the Chinese see the size of their market as an attraction to FDI? Do they want foreign investors to be catering to the domestic market or would they prefer to see export oriented firms established?

Two of the factors least considered in the FDI literature, but which seem to be increasingly important in the case of China, are culture and the governance of firms. Differences in both, compared with the originating country, can raise the cost of operation in the host country and hence act as a factor discouraging FDI. In the case of culture, Choi (2004), using data on bilateral FDI from the OECD between 1982 and 1997, found that the existence of a common language between the country of outflow and the country of inflow was an important determinant of FDI. In relation to governance, Ye and Valentine (2000) point to the common but often obscure reference in the literature to commercial legal problems for foreign companies investing in China with relatively high levels of disputes. They document the problems which include the importance placed on personal relations, lack of transactions being documented, the fact that Chinese law is more likely to see a contract as a framework rather than detailed clauses that must be followed and that the Chinese Government, particularly when corrupt officials are involved, appears less able and inclined to assist foreign investors when disputes occur. Woo (2000:161) argues for reform of China's financial institutions and State Owned Enterprises (SOEs) 'including the creation of a prudential regulatory body to reduce excessive risk-taking by banks'. Concern over Chinese investment systems is a recurring theme in the FTA negotiations. Wang (2000) finds that the informal nature of personal networks has assisted FDI thus partially compensating for the problems associated with Chinese institutions. Do the Chinese recognise that foreigners perceive difficulty in dealing with China because of differences in culture and governance? Is there any indication that the Chinese are prepared to deal with these matters to alleviate the concerns of foreign investors?

There are clearly policy influences on FDI patterns and it cannot be assumed that policies, in any area, will have the same influence on FDI in all sectors of a transitional economy (see OECD, 2003). Increasingly, an important area of study has been the impact of capital account liberalisation on FDI (see Singh, 2003). From an internal Chinese perspective, Pingyao (2002) points to the reform of the foreign investment regime in China as an important explanation for the rise in 
FDI. Pingyao argues that the reforms were driven by a desire to acquire access to external technology and to reform the moribund SOEs through the establishment of joint ventures. Do the Chinese still retain this desire? Is it likely that reforms directed at capital inflow will be based on a desire to access western technology?

Finally, we consider why the Chinese might be interested in entering into a FTA (which includes the freeing up of capital movements) with a country like Australia. Usually, an explanation will be provided in terms of the beneficial impacts that the agreement can be expected to have on the economy in terms of the relationship between FDI (and trade) and economic growth. Hsiao and Shen (2003) point out that, in accordance with the Harrod-Domar model of growth, capital formation plays a crucial role. They note that FDI enhances both the stock of capital and its efficiency. Their quantitative work on China supports the OECD (2000) view that FDI is an important source of capital growth and contributes to additional jobs and enhanced skills. However, they also found that the relationship between FDI and growth appeared to be two-way, confirming the earlier findings such as those by Shan, Tian and Sun (1997) that FDI and economic growth have reinforced each other both in China and elsewhere.

Overall, the evidence appears strong that FDI generates otherwise unattainable levels of growth (see Sun, 1998). Again, there are qualifications persistent throughout the literature. Several researchers have advanced reasons for the relatively high level of Chinese economic growth and the connection to FDI (see $\mathrm{Hu}$ and Khan, 1997; Hsiao and Hsiao 2004; Zhang and van Witteloostuijn, 2004). The transfer of resources, particularly labour from agriculture to manufacturing, expansion of total exports and foreign investment aimed at securing low cost production and an extensive domestic market are important causal factors here. Evidence to date is generally supportive of the proposition that FDI is causally related to economic growth through a primary aim of export promotion (see Lui et. al., 2002). Are the Chinese aware of the likely positive impact that FDI might have on economic growth? Would such an impact lead them to pursue policies that might lead to a more rapid growth of the economy?

\section{Methodology}

Data on Chinese opinion on the issues canvassed above were collected in surveys of 1,515 students and 74 senior academics from two Chinese universities Tianjin University of Commerce and Changchun Taxation University. Tianjin is a large city of about 10 million people some $150 \mathrm{~km}$ north-east of Beijing and likely to be influenced by Beijing's international business climate. Students there are thus relatively more affected by China's international business and cultural interactions. Changchun is a medium-sized city of about 3 million people in Jilin province of northeast China. It has an older industrial structure in an interesting location between the relatively high investment centres on the coast and the relatively low investment inland centres. Changchun is less 'westernised' than larger cities such as Shanghai and Beijing. It was therefore expected that opinions from Changchun respondents would be, in a sense, more 'Chinese'. Thus, 
combining the two samples was expected to provide a more balanced representation of the views of Chinese students and academics as a whole.

The surveys, based on written questionnaires and direct interviews (of academic staff only), were conducted in April-June, 2005. Other studies in the general area of free trade agreements have also employed the survey method (see Rugman and Verbeke, 1990). The respondents were not chosen randomly. For the student survey, undergraduate and post-graduate students from commerce courses were invited to participate on a voluntary basis. The questionnaire was administered to some 1,950 students and resulted in 1,515 usable responses, a 77.7 per cent response rate. Ready access to the groups of interviewees was a primary consideration in our choice. However, in each case, the members of the groups met the criteria laid down by Lloyd (2006) of being independent and informed and are likely (especially in the case of business students) to be central to the development of public opinion that will impact upon future policy. The corporate governance pattern in China has been changing rapidly in recent years and current students will become a part of the business leadership. Their opinions on global partnerships such as foreign trade are thus important. Moreover, born during the post-reform period, current university students have grown up in a relatively open (by Chinese standards) political, social and economic environment making them more likely to express their opinions than would previous generations. Thus, although the level of maturity and experience of the students cannot be compared with that of current business practitioners, their views cannot be ignored when considering future directions. Further, an advantage of surveying commerce students is that they represent the next generation of business leaders in China and, in their university programs, are likely to have been exposed to, and developed opinions on, the issues in question which they will take into their imminent business careers. In other words, they are technically competent to express opinions on the matters at hand and are therefore likely to play a significant role in the formation of a public opinion more open to economic reforms.

About half the student respondents (734 students) were from two subject areas only (economics and international trade). Another four subjects covered 379 students (25 per cent). Slightly more than eight per cent (126 students) were from post-graduate courses, mainly from accounting, international trade, and finance. There were significantly more female students among respondents (65.9 per cent), generally in line with the student enrolment pattern in the universities.

Senior academic staff teaching commerce subjects such as international trade, economics, banking, management, marketing and accounting were surveyed and interviewed. About 200 questionnaires were circulated among staff and 74 usable responses were obtained, a 37 per cent response rate. The survey was conducted in two stages. An open-ended questionnaire was used in an initial survey. In the second stage, interviews were conducted with more interested staff members. The interviews were limited to 12 academics only who were willing to, and could moderately communicate in English. Each interview lasted about 30 minutes. General views obtained from questionnaire responses and direct interviews were quite mixed and can broadly be referred to as uncertain. Most of the respondents 
and interviewees spoke in general terms, without an extensive knowledge of Australia. It appeared that the academics were not used to relatively open discussion. The responses were conservative and guarded to a large extent.

\section{Survey Results}

Students were asked to express their opinions on 21 issues (questions) related to FDI in China. Questionnaires with less than 5 per cent of non-responses were included as usable cases. Results of the student survey on a range of dimensions related to FDI in China are presented in Table 1. Detailed statistical significance tests of samples were not conducted as they are not very relevant for categorical data obtained through these surveys. The survey questions sought opinions on issues that are difficult to group or design a theoretical model based on them. Tests were done in certain areas using demographic features (for example, gender) where results are mostly significant. Standard deviations of responses were estimated in each area and were low (less than 1.0) in most cases. They signify a relatively unified nature of responses. The academics' responses are not presented in tabular form as they related to open-ended questions. They are analysed below along with student responses on respective issues.

The academics agreed that a close relationship existed between FDI and export performance, but were uncertain as to the nature of the causality. On the specific issue of the proposed FTA, the academics stated in general terms that it would be beneficial for both economies. However, during interviews several academics questioned whether the proposed FTA would improve investment flows in particular. They explained that it would be advantageous for Chinese companies to continue to export manufactured products rather than setting up production bases in Australia where labour costs would be substantially higher. Moreover, if Chinese companies had sufficient resources to invest overseas they were more likely to invest in the neighbouring region where they had better knowledge and greater cultural affinity. They stated that return on investment in China in general and on FDI, in particular, was becoming more competitive.

Students strongly supported the freeing up of trade and capital movement. While only 15 per cent were prepared to say that political considerations alone are important, 58 per cent stated that restrictions on the flow of funds inhibited FDI. Only 31 per cent considered that pegged exchange rates impacted beneficially on FDI while 46 per cent supported a floating exchange rate. This is particularly significant in the light of the current debate over the Chinese exchange rate and the move to tie the RMB to a basket of currencies rather than the USD.

On the other hand, the Chinese academics agreed that a stable exchange rate was necessary with the majority of them favouring a pegged rate. They felt that floating the RMB at this point in time would be detrimental to Chinese interests in both trade and investment markets. This is likely to reflect a more conservative attitude in general by older Chinese. It also suggests that the younger Chinese are not bound by the past and are prepared to be more open and outward looking. This difference between the two groups is also evident on other issues. 
Table 1: Determinants of Foreign Investment in China — Responses of Surveyed Students

\begin{tabular}{|c|c|c|c|c|c|c|}
\hline Issue & Responses & $\begin{array}{c}\text { Strongly } \\
\text { Agree }\end{array}$ & Agree & Indifferent & Disagree & $\begin{array}{l}\text { Strongly } \\
\text { Disagree }\end{array}$ \\
\hline & No. & & & per cent & & \\
\hline Political considerations only & 1,513 & 4.2 & 10.6 & 6.7 & 65.1 & 13.4 \\
\hline Level of restrictions on inflow \& outflow of funds & 1,505 & 6.4 & 51.2 & 12.3 & 27.6 & 2.5 \\
\hline Size of a country (in terms of population) & 1,505 & 9.7 & 39.0 & 13.3 & 34.5 & 3.5 \\
\hline Fixed (pegged) foreign exchange rate is the best policy & 1,496 & 3.8 & 27.3 & 22.7 & 43.7 & 2.5 \\
\hline Favourable foreign exchange rate & 1,488 & 12.2 & 61.2 & 12.4 & 12.8 & 1.5 \\
\hline Economic stability & 1,502 & 28.6 & 47.2 & 11.0 & 12.4 & 0.9 \\
\hline Economic growth & 1,477 & 18.8 & 54.0 & 13.7 & 12.6 & 0.9 \\
\hline Fiscal benefits & 1,500 & 14.6 & 50.7 & 15.9 & 16.6 & 2.1 \\
\hline Availability of cheaper resources & 1,510 & 5.0 & 30.5 & 23.1 & 37.4 & 4.0 \\
\hline Low wage rate & 1,511 & 7.3 & 38.6 & 19.1 & 30.1 & 4.8 \\
\hline Level (quality) of working conditions is irrelevant & 1,495 & 3.5 & 10.6 & 10.6 & 54.6 & 20.7 \\
\hline Good infrastructure facilities & 1,499 & 29.0 & 56.2 & 8.3 & 5.3 & 1.3 \\
\hline Efficient and fair justice system & 1,507 & 25.9 & 57.0 & 11.6 & 4.8 & 0.7 \\
\hline Geographical location & 1,493 & 15.7 & 61.0 & 16.1 & 6.6 & 0.7 \\
\hline Experience of existing foreign investors & 1,497 & 9.1 & 48.8 & 26.9 & 13.7 & 1.6 \\
\hline Availability of quality manpower & 1,510 & 14.2 & 47.8 & 22.3 & 14.3 & 1.5 \\
\hline Existence of good corporate governance & 1,497 & 12.2 & 65.0 & 14.3 & 7.7 & 0.8 \\
\hline Foreign investment helps to increase exports in collaborator's country & 1,508 & 6.6 & 57.4 & 22.0 & 12.7 & 1.2 \\
\hline Foreign investment helps to increase exports in any country & 1,509 & 6.6 & 25.5 & 23.5 & 40.7 & 3.6 \\
\hline Trade relationship is a precondition for attracting foreign investments & 1,500 & 8.5 & 56.5 & 21.5 & 12.7 & 0.7 \\
\hline $\begin{array}{l}\text { Trade relationship and financial collaboration are completely } \\
\text { independent of each other }\end{array}$ & 1,503 & 3.4 & 10.9 & 10.4 & 53.4 & 21.9 \\
\hline
\end{tabular}


In general, the findings suggest that the Chinese student respondents were clearly in favour of foreign investment and new technologies. They had a positive outlook towards Australia, although a lack of detailed knowledge about Australia acted as a limiting factor. Their perception about the Australian corporate sector was very positive and they clearly considered that it would be beneficial for Chinese companies to associate with their Australian counterparts.

Both groups were asked about causal factors of FDI growth. Their responses indicate that they had a good understanding of the factors believed to contribute to FDI as expressed in the theoretical and empirical literature. Previous empirical work has consistently emphasized the importance of good infrastructure as being essential in attracting FDI. The students were aware of this as 85 per cent of respondents agreed that good infrastructure was an important determinant. The academics also considered infrastructure important and (see below) considered that it was the responsibility of government to put infrastructure in place.

As we have seen, some debate continues over the importance of cheap resources and, in particular, labour market factors, in attracting FDI. The students were clearly focused on the development potential of FDI rather than on its exploitative possibilities. While they believed that the quality of working conditions was important in attracting FDI, only 46 per cent identified low wages as being important. Although a majority (62 per cent) identified the availability of skilled labour as being important, this response was much lower than might have been expected. These findings only add to the confusion surrounding the previous conflicting empirical findings about the price and quality of labour as a determinant of FDI. However, helping reconcile these findings is the fact that only 35 per cent of students considered that FDI was attracted to China due to access to cheap resources. The conclusion may reasonably be drawn that they believe that foreign companies are coming to China not to exploit cheap resources and export their product from China, but to capture a share of China's enormous market. The latter, it appeared, was to be encouraged. On the other hand, it is interesting to note that, in contrast, the academics held that the availability of a relatively cheap and disciplined labour force acted as a strong determinant of FDI.

The students rated the macroeconomic considerations as impacting on FDI highly. Economic stability and economic growth were considered important by 76 per cent and 73 per cent respectively, a finding consistent with the literature. However, the size of the market (measured by population) was seen to be far less important (49 per cent) than many other contributing factors. The students had apparently assigned higher importance to longer term factors than to popular issues. Again, this is in contrast to the academics who considered that China's large market was a strong inducement for foreigners to invest in the country.

There was a clear understanding by students that firms are unwilling to invest in a country where the 'culture shock' outweighs any firm-specific advantage. In particular, they stated that FDI could be encouraged by the development of an efficient and fair system of justice (83 per cent) which reduces business costs. There was also a high recognition (77 per cent) of the need to establish a corporate culture that exhibited good governance practices. This indicates a belief that 
continued FDI growth could not be assured if institutional problems highlighted by Wang (2000) were not overcome. They clearly believed that development of personal networks alone would be insufficient to attract investment.

Cultural issues were also highlighted by several academics during interviews. They felt that foreign investment from the neighbouring region and from Chinese expatriates offer greater long term potential for China. Several were sceptical about western investment although they agreed that it was necessary to maintain high levels of economic and trade growth. They also argued that the possibility of capital taking flight was more likely in the case of western investors, some referring to 'Fire Sale FDI' (see Krugman, 1998). Interestingly, none of the academics were ready to offer strong opinions about the absence of an appropriate intellectual property protection system in China. They did not consider it as a major hindrance to the inflow of foreign investment, even from western investors. However, they thought that it may be a problem in relation to trade relationships. On the other hand, the academics did consider that the Chinese environmental laws should be improved to attract foreign investors on a longer term basis.

The major difference between the responses of students and academics is apparently based on their relative perspectives. Students were more concerned with short and medium term factors whereas the academics were more cautious and viewed factors from longer term perspectives. Academics were more positive about the role of the Government and felt quite secure under Government policies.

On policy action, the attitude of students was clearly in line with the views of Pingyao (2002) and Mastel (2004) that policy issues are important in attracting FDI. As we have seen, the students were supportive of capital market policies to free-up the movement of funds and supported exchange rate flexibility and policies to enhance the development of infrastructure. In addition, although $\mathrm{Ma}$ (2000) downplays the importance of tax concessions in attracting FDI, the student responses indicate that they believe somewhat differently. Nearly 65 per cent of respondents considered fiscal benefits to be important.

Academics and students had somewhat different attitudes toward policy. The students' view appears to be that policy creates the environment in which decisions can be made by the market. The academics tended to advocate a more interventionist role for government. They pointed to concentrations of investment in the coastal areas, and particularly in the Shanghai region, and argued that it was becoming a growing concern for China. They felt that the Government must play a leading role in spreading foreign investment more evenly so that less developed regions could experience its benefits. They argued that under the existing political system the direction of economic activity in this way remains possible. Thus, in their opinion, political factors are still very relevant whereas the students felt such political factors were unimportant. Moreover, the academics thought that provision of preferential treatment to foreign investors through infrastructure support and tax flexibility, for example, must be the responsibility of the Government. However, the academics acknowledged their country's entry into the WTO was an important policy decision that was helping to open up their economy. The majority felt that China was sincere in its commitments towards 
the WTO and that the opening of the economy in both trade and investment was likely to continue.

Despite their differences in attitude on some matters, both the students and the academics seemed to be comfortable with the proposition that enhanced FDI would be beneficial for the Chinese economy and therefore to be encouraged. A majority of the academics considered Chinese economic growth (pace of growth, to be specific) both a cause and an effect of FDI in recent years. The students also identified FDI as a cause of export growth and therefore beneficial for the country. As explained earlier, students have strong opinions on trade and investment relationships, the role of political factors and the quality of working conditions.

\section{Conclusions}

Australia and China are considering establishing a Free Trade Agreement. Part of the proposal includes measures that will enhance the flow of capital between the two countries. The successful adoption of an FTA between the two countries is likely to enhance the economic development of both. However, the adoption of policies to enhance both trade and investment flows between countries is likely to be dependent on supportive attitudes from those who have some impact on the decision-making processes. In Australia, there has been a wide canvassing of the proposal to enter into an FTA with China from the perspective of trade flows, but less consideration has been given to flows of capital. Further, almost nothing is known of public attitudes to the proposal in China. Knowledge of a positive attitude on the part of the Chinese would assist in developing confidence amongst potential Australian investors who might, at present, have some reluctance in investing in a relatively unknown economy. It is also important to know if the Chinese are likely to be willing to bring about institutional changes in their country that will encourage, rather than hinder, the free flow of trade and capital.

In line with previous research, there is a presumption in China that increased inflows of foreign capital are associated with economic growth. There is also a strong belief that this cause and effect results from the increased productivity of Chinese business resulting from their exposure to improved business management and international trading practices that accompany FDI. Accepting that FDI and growth are aligned, the Chinese are keen to encourage FDI. They realise that the flow of FDI depends on a range of factors and it increases only when most of these factors are favourable. There is wide acceptance amongst the Chinese that an FTA between countries can facilitate investment flows. Our research indicates that the Chinese, as well as the Australians, believe that a strong relationship exists between trade and capital flows and that the encouragement of one will be of benefit to the other. In order to assure a continued flow of FDI into China, the respondents considered it important that they continue the process of opening their economy and developing institutions. In particular, they recognise that funds from the west will only be attracted where measures are taken to ensure an openness, transparency and certainty in economic relationships. These are the very issues that Australian public opinion indicates need to be addressed. 
As per the findings of our surveys, China is open to FDI. The Chinese consider that there is profit potential. The Chinese do not have an extensive knowledge of Australia and the Australian Government needs to continue and perhaps expand the promotion of Australian business in China. Attitudes towards the market are changing in China. Although older Chinese (senior academics) still support Government involvement, younger Chinese clearly favour a freer market. Australia could promote its business capabilities more extensively in China, given the strength of large American and European companies. Several issues concerning governance remain problems but the Chinese are aware of these. Australian companies need to be assured that the Chinese authorities are working to overcome them. Investment opportunities are no longer confined to the Special Economic Zones and are emerging in the northern provinces.

However, it should not be considered that conditions are perfect for enhanced flows of capital between Australia and China. Attitudes change slowly and some of the more entrenched beliefs will take longer to overcome. The older Chinese favour investment in 'Asian' economies because of their greater cultural affinity. Fortunately for Australia, the young do not share these views and are more willing to explore a wider perspective. They are also more open to freeing up capital movements, including the exchange rate. They seem eager to be involved in the global economy and believe that they can compete on an equal basis with the rest of the world. They no longer believe that China's economic strength lies in the exploitation of cheap labour but rather in harnessing modern technologies.

Both the students and the academics understood the importance of good infrastructure in attracting FDI. However, only the older Chinese considered political considerations with respect to directing infrastructure developments as being important. The young were less concerned with 'backing winners' than with developing free and transparent markets and institutions which they saw as a precondition for continued high levels of FDI.

In summary, there is good support in China for an FTA with Australia, including FDI. The young are more aware of the need for a freer market in order to maximise the benefits to China from such proposals. To the extent that the Australian government can reach agreement with the Chinese government on establishing an FTA which involves FDI, the results of this research indicate that it could provide an important framework for mutual economic development.

\section{References}

Bajo-Rubio, O. and M. Montero-Munoz (2001), 'Foreign Direct Investment and Trade: A Causality Analysis’, Open Economies Review 12(3):305-323.

Binh, N. and J. Haughton (2002), 'Trade Liberalization and Foreign Direct Investment in Vietnam’, ASEAN Economic Bulletin 19(3):302-318.

Chakrabarti, A. (2001), 'The Determinants of Foreign Direct Investment: Sensitivity Analyses of Cross-Country Regressions', Kyklos 54:89-114. 
Cheng, L. and Y. Kwan (2000a), 'What Are the Determinants of the Location of Foreign Direct Investment? The Chinese Experience', Journal of International Economics 51(99):379-400.

Cheng, L. and Y. Kwan (2000b), 'The Location of Foreign Direct Investment in Chinese Regions: Further Analysis of Labour Quality’, pp. 213-238 in I. Takatoshi and A. Krueger (eds), The Role of Foreign Direct Investment in East Asian Economic Development, The University of Chicago Press, Chicago and London.

Choi, C. (2004), 'Foreign Direct Investment and Income Convergence', Applied Economics 36(10):1045-49.

De Mello Jr, L. and K. Fukasaku (2000), 'Trade and Foreign Direct Investment in Latin America and Southeast Asia: Temporal Causality Analysis', Journal of International Development 12(7):903-924.

Gao, T. (2002), 'Labor Quality and the Location of Foreign Direct Investment Evidence from FDI in China by Investing Country', Unpublished Manuscript, University of Missouri, Department of Economics.

Hsiao, C. and Y. Shen (2003), 'Foreign Direct Investment and Economic Growth: The Importance of Institutions and Urbanization', Economic Development and Cultural Change 51(4):883-896.

Hsiao, F. and M. Hsiao (2004), 'The Chaotic Attractor of Foreign Direct Investment Why China? A Panel Data Analysis’, Journal of Asian Economics 15:641-70.

$\mathrm{Hu}$, Z. and M. Khan (1997), 'Why is China Growing So Fast?', International Monetary Fund Staff Papers 44(1):103-31.

Kerr, I. and V. Peter (2001), 'The Determinants of Foreign Direct Investment in China', Paper presented at the $30^{\text {th }}$ Annual Conference of Economists, University of Western Australia, Perth, September 23-26.

Krugman, P. (1998), 'Fire-Sale FDI', Paper presented at NBER conference on Capital Flows to Emerging Markets, MIT, February 20-21.

Lewer, J. and N. Terry (2003), 'Capital Account and Foreign Direct Investment Policies in the Late Nineties: What Effect on Trade?’, Asian Economic Bulletin 20(3):256-271.

Lloyd, P. (2006), 'Trade Policy: The Role of Public Enquiries', Economic Papers 25(1):1-16.

Lui, X., P. Burridge and P. Sinclair (2002), 'Relationships Between Economic Growth, foreign Direct Investment and Trade: Evidence from China', Applied Economics 34(11):1433-40.

Ma, J. (2000), The Chinese Economy in the 1990s, Macmillan, Basingstoke, Hampshire.

Mastel, G. (2004), 'The Rise of the Free Trade Agreement', Challenge 47(4):41-61.

Organisation for Economic Co-operation and Development (2000), 'Main Determinants and Impacts of Foreign Direct Investment in China’s Economy’, Working Papers on International Investment, Number 2000/4.

Organisation for Economic Co-operation and Development (2003), 'Policy Influences on Foreign Direct Investment', OECD Outlook 73:514-30. 
Pantulu, J. and P. Poon (2003), 'Foreign Direct Investment and International Trade: Evidence from the US and Japan’, Journal of Economic Geography 3(3):241-259.

Pingyao, L. (2002), 'Foreign Direct Investment in China: Recent Trends and Patterns', China and World Economy 2:25-32.

Rob, R. and N. Vettas (2003), 'Foreign Direct Investment and Exports with Growing Demand', The Review of Economic Studies 70(244):629-648.

Rugman, A. M. and A. Verbeke (1990), 'Multinational Corporate Strategy and the Canada-US Free Trade Agreement’, Management International Review 30(3):253-66.

Sethi, D.; S. Guisinger; S. Phelan and D. Berg (2003), 'Trends in Foreign Investment Flows: A theoretical and Empirical Analysis', Journal of International Business Studies 34(4):315-26.

Shan, J., G. Tian and F. Sun (1997), 'The FDI-led Growth Hypothesis: Further Econometric Evidence from China’, Working Paper, The Australian National University, Economics Division, Research School of Pacific and Asian Studies.

Singh, A. (2003), 'Capital Account Liberalization, Free Long-Term Capital Flows, Financial Crises and Economic Development’, Eastern Economic Journal 29(2):191-216.

Sun, H. (1998), 'Macroeconomic Impact of Direct Foreign Investment in China: 197996’, The World Economy 21(5):675-94.

Taylor, R. (2003), 'China’s Consumer Revolution: Distribution Reform, Foreign Investment and the Impact of the WTO', Asian Business and Management 2(2):187-97.

Wang, H. (2000), 'Informal institutions and foreign investment in China', The Pacific Review 13(4):525-56.

Woo, W. (2000), 'China: Confronting Restructuring and Stability’, pp. 127-164 in W. Woo, J. Sachs and K. Schwab (eds), The Asian Financial Crisis: Lessons for a Resilient Asia, MIT Press, Cambridge.

Ye, A. and S. Valentine (2000), 'More Haste, Less Speed: The Secret to Investing in China’, International Financial Law Review 19(1):17-19.

Zhang, X. (2000), China's Trade Patterns and International Comparative Advantage, Macmillan, Hampshire \& London.

Zhang, K. (2001), 'What Attracts Foreign Multinational Corporations to China?', Contemporary Economic Policy 19(3):336-46.

Zhang, J. and A. van Witteloostuijn (2004), 'Economic Openness and Trade Linkages of China: An Empirical Study of the Determinants of Chinese Trade Intensities from 1993 to1999', Review of World Economics 140(2):254-81.

The authors acknowledge the benefit they have received from the comments of the editor and two anonymous referees, but remain responsible for any errors. The authors also acknowledge financial benefits under 'Asia-Pacific Research Project Grant' to conduct this research and Special Studies Programme of the University. 